\title{
Synthesis of Ophiocerin D
}

\author{
Dong-Min Lee and Han-Young Kang ${ }^{\star}$ \\ Deparment of Chemistry, Chungbuk National Lniversitw, Cheongit, Chungbuk 361-763, Korea \\ "E-mail: hykangiâchughbuk.ac.hr \\ Received July 20, 2009, Accepted July 30, 2009
}

Key Words: Ophiocerin. Total șynthesis. Stereoselective șyntheșis. Tetrahỵdropy ran. Natural product

Ophiocerins are the compounds isolated by Gloer group during the investigations on aquatic fungi living in fresh water. They are tetrahydropy ran-containing natural products and a total of four ophiocerins are known (Figure 1). ${ }^{1}$

Because tetrahydropyran rings have been an important structural part in many known natural products having biological activities. ${ }^{2}$ synthesis of ophiocerins has attracted attention of synthetic chemists. Yadav and co-workers investigated the synthesis of opliocerin B (2) and C (3). Their total synthesis was based on the asymmetric dihydrosylation to set up the required stereogenic centers. ${ }^{3}$ Our interests in ophiocerins have resulted in the total synthesis of ophiocerin $\mathrm{A}-\mathrm{C}(1-3)$ by

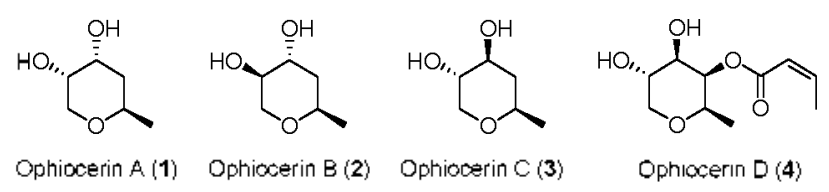

Figure 1. Ophiocerins.

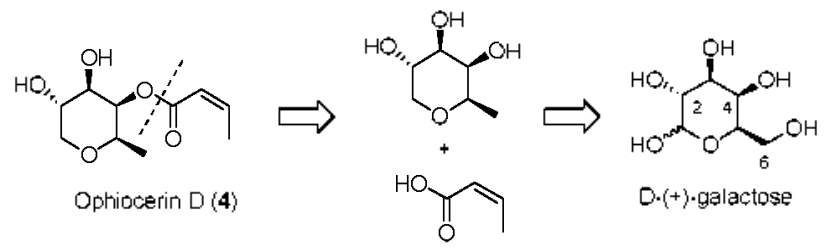

Scheme 1. Retrosynthesis of ophiocerin D (4) carbohydrate-based approaches. ${ }^{4}$ After completing the synthesis of ophiocerin $\mathrm{A}-\mathrm{C}(\mathbf{1 - 3})$, we have been naturally interested in the synthesis of ophiocerin D (4). A synthesis of ophiocerin D (4) was reported recently starting from xylose. They used asy mmetric dihydrosylation as a key step to implement two stereogenic centers and the resulting acyclic precursor was cyclized to prepare the tetralydropyran ring with needed stereochemistry. Herein we report a more efficient and simpler carbohydrate-based approach to the synthesis of ophiocerin D (t). Scheme 1 shows the retrosynthetic analysis of opliocerin D (4).

Ophiocerin D ( 4 ) would be derived from the acid and the sugar parts. which should be synthesized from the D-(+)galactose with the right stereochemical relationslup along the tetrahydropyran ring. It is first required to synthesize the core sugar part and our approach to the core part is summarized in Scheme 2. First, D-(+)-galactose was transformed to the bromosugar 5 by a two-step procedure [(1) $\mathrm{Ac}_{2} \mathrm{O}$. py ridine. (2) $\left.\mathrm{HBr}\right]$ in excellent yield. ${ }^{6}$ Debromination was successfully achieved to provide the debromosugar 6 and it was hydrolyzed to produce compound $7 .^{\prime}$ In order to differentiate four hydroxy groups in 7, we first protected C -4 and $\mathrm{C}-6$ hydroxy groups (according to the galactose numbering system in Scheme 1) (benzaldehyde dimethyl acetal. $p-\mathrm{TsOH})^{8}$ and acetylated the two remaining hyddroxy groups at $\mathrm{C}-2$ and $\mathrm{C}-3$. Utilization of the selective bromination method $\left(\mathrm{BaCO}_{5}, \mathrm{NBS}, \mathrm{AIBN}\right)$ allowed bromination at $\mathrm{C}-6$ as well as protection at $\mathrm{C}-4$ hydroxy group with the benzoyl functionality."

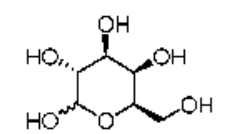

$\frac{\mathrm{AC}_{2} \mathrm{O} \text {. Pyridine }}{99 \%}$

D-(+)-galactose

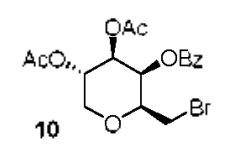

$$
\frac{\mathrm{BaCO}_{3} \cdot \mathrm{NBS}}{\mathrm{CCl}_{4} .88 \%}
$$

$\mathrm{B} \mathrm{U}_{3} \mathrm{SnH}, \mathrm{AIBN}$

$\mathrm{Bu} u_{3} \mathrm{SnH}, \mathrm{AlBN}$
benzene, $96 \%$

$\longrightarrow$ AcO,

11

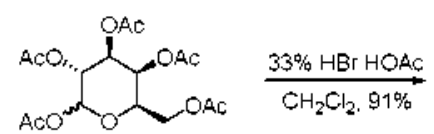<smiles>CC(=O)O[C@H]1CO[C@H]2COC(c3ccccc3)OC2[C@H]1OC(C)=O</smiles>

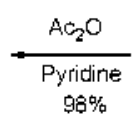

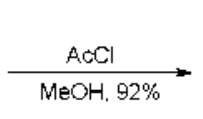<smiles>CCO[C@@H]1[C@@H](O)[C@H](O)CO[C@@H]1C</smiles>

12

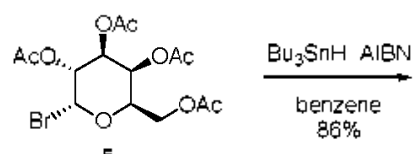

5<smiles>O[C@H]1CO[C@@H]2COC(c3ccccc3)O[C@H]2[C@H]1O</smiles>

8

2-methoxypropene.

CSA. $60^{\circ} \mathrm{C}$

DMF : $86 \%$<smiles>CCCCCCCCO</smiles>

13

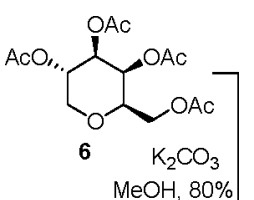

berizaldehyde $\frac{\text { dimethyl acetal }}{\text { Tim }}$ $46 \%$<smiles>CCCCCCO</smiles>

7

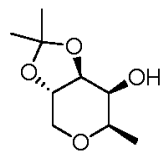

14

Scheme 2. Synthesis of the sugar-derived part 14 


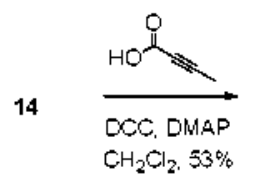<smiles>C/C=C\C(=O)O[C@@H]1[C@@H](O)[C@@H](O)CO[C@@H]1C</smiles>

Ophiocerin D(4)

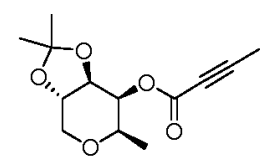

16

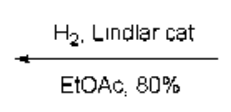

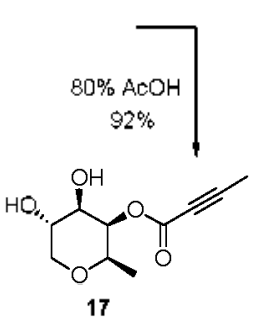

Scheme 3. Total synthesis of ophiocerin D (4)

Next, debromination ${ }^{9}$ successfully provided the C- 6 deoxygenated and fully protected sugar derivative 11. The following issue is to find out the procedure for selective deprotection of acetyl groups with a benzoyl group remained intact. Hydrolysis under aqueous basic conditions, however, resulted in the removal of all the ester groups. After some experimentation in search of the reaction conditions. selective hydrolysis of the acetates was finally achieved ( $\mathrm{AcCl}$. $\mathrm{MeOH}$ ) ${ }^{110}$ to provide 12 . It is worthwhile to mention that hy'drolysis with $p$ - $\mathrm{TsOH}$ (in $\mathrm{CH}_{2} \mathrm{Cl}_{y}$ ) $\mathrm{MeOH}$ ) was slow and provided a mixture of partially and fully hydrolyzed products. After converting the diol 12 to the acetonide 13 (2-methoxyproene. CSA $),{ }^{11}$ we were able to remove the benzoyl group $(\mathrm{KOH} . \mathrm{MeOH})$ to secure the intermediate $1+$ successfully.

Esterification is required for completion of the synthesis. We naively first tried the esterification of $\mathbf{1 +}$ with cis-2butenoic acid. ${ }^{13}$ But we soon realized that the esterification gave rise to a mixture of cis- and trans-isomers (15a and 15b) (Eq. 1) under the conditions (DCC and Yamaguchi esterification) we examined. We found that subjecting the pure desired ester 15a to the esterification conditions described previously led to the isomerization of the double bond geometry ending up with a mixture of 15a and 15b.

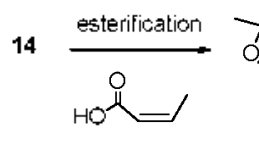<smiles>C/C=C\C1OC2COC3COC(C3)C2O1</smiles>

$15 a$

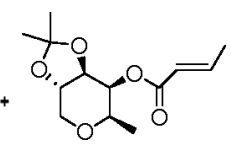

$16 \mathrm{~b}$
The required side chain was introduced by esterification with 2-butynoic acid in decent yield (DCC. DMAP) ${ }^{1+}(53 \%)$ (Scheme 3 ). The Yamaguchi protocol did not provide any better yield. Removal of the acetonide protecting group ${ }^{\text {ss }}$ followed by the selective hydrogenation with Lindlar catalyst provided ophiocerin $\mathrm{D}(\boldsymbol{t})$. The spectroscopic data as well as optical rotation were identical to those of the natural product. ${ }^{1}$

In conclusion. ophiocerin D (4) has been syythesized from galactose in a total of 14 steps. This synthesis has an advantage in the use of cheap and easily available D-(+)-galactose which already has all the required stereochenucal relationships for the sy nthesis of ophiocerin $D(4)$. The number of steps involved in this synthesis is shorter than that in the first synthesis ${ }^{5}(14$ steps from D-galactose $u s$. more than 17 steps from D-sylose). This synthesis presents an efficient way to differentiate stereocenters around galactose ring and therefore. could be used for the stythesis of other natural products with similar substitution patterns on the tetralyydropyaran rings. Selectivity in hydroly'sis to differentiate acetyl groups from a benzoyl group is an interesting feature and could be valuable for the syythesis of related compounds. too. The pendent cis-butenoyl group is quite labile. readily isomerized to the trans isomer and needed to be installed at the last step.

Aclonowledgments. This work was supported by the research grant of the Chungbuk National University in 2007.

\section{References}

1. Reátequi, R. F; Gloer, J. B.; Campbell, J;; Shearer, C. A. J. Nat. Prod. 2005, 68, 701-705.

2. Clarke, P. A.; Santos, S. Eur. J. Org. Chem. 2006, 2045-2053.

3. Yadav, I. S.: Lakshmi, P. N.: Harshavardhan, S. J : Subba Reddy, B. V. Sinlet 2007, 1945-1947.

4. (1) Lee, D.-M,; Lee, H.; Kang, H.-Y. Bull. Konan Chent. Soc. 2008, 29, 535-536. (2) Lee, D.-M.; Kang, H.-Y. Bull. Kowen Chem. Soc. 2008, 29, 1671-1678.

5. Sharma, G. V. M.; Damera, K. Tetrahedron: Asmmetry 2008. 19. 2092-2095

6. Mitchell, S. A.; Pratt, M. R.; Hruby, V. T.; Polt, R. J. Org. Chem. 2001, 66, 2327-2342.

7. Ruttens, B.: Blom, P.; Hoof, S. V: Hubrecht, I.; Eycken, I. V. J. Oig. Chem, 2007, 72, 5514-5522.

8. Nie, X.: Wang, G. J. Org. Chem 2005, 70, 8687-8692.

9. Groneberg, R. D.; Miyazaki, T.; Stylianides, N. A.; Schulze, T. I.; Stahl, W.; Schreiner, E. P.; Suzuki, T.; Iwabuchi, Y.; Smith, A. L. Nicolaou, K. C. J. Am. Chem. Soc. 1993, 115, 7593-7611.

10. Zhang, I; Kong. F. Tetrahedron 2003, 59, 1429-1441.

11. Phillips, D.: Chamberlin, A. R. J. Ong. Chem 2002,67,3194-3201.

12. Plé, K.; Chwalek, M.; Voutquenne-Nazabadioko, L. Eur: J. Org. Chem. 2004, 1588-1603.

13. Rappe, C. Org. Snth. Coll. Iol. I7 1988, 711-714.

14. Ma, S.: Zhu, G.; Lu, X. J. Org. Chem. 1993, 58, $3692-3696$.

15. Dorta, R. L.; Martin, A.; Salazar, J. A.: Suarez, E. J. Oig. Chem. $1998,63,2251-2261$. 